\title{
A Novel Approach to Assess Oral Feeding Skills of Preterm Infants
}

\author{
C. Lau E.O. Smith \\ Department of Pediatrics, Baylor College of Medicine, Houston Tex., USA
}

\section{Key Words}

Very low birth weight $\cdot$ Bottle feeding $\cdot$ Prematurity $\cdot$ Oral feeding evaluation

\begin{abstract}
Background: There is no well-defined means to identify the level of oral feeding skills (OFS) in preterm infants. Objective: To determine whether OFS as reflected by the combination of proficiency (PRO, \% $\mathrm{ml}$ taken during the first $5 \mathrm{~min} / \mathrm{ml}$ prescribed) and rate of milk transfer (RT, $\mathrm{ml} / \mathrm{min}$ ) correlates with gestational age (GA), oral feeding performance (OT, \%ml taken during a feeding $/ \mathrm{ml}$ prescribed) and days from start to independent oral feeding (SOF-IOF). Our working premises are that PRO is reflective of infants' actual feeding skills when fatigue is minimal and RT, monitored over an entire feeding session, reflects their overall skills when fatigue comes into play. Methods: Infants (26-36 weeks GA) with prematurity as their principal diagnosis were recruited and monitored at their first oral feeding. GA was divided into 3 strata, 26-29, 30-33, and 34-36 weeks GA. OFS was divided into 4 levels delineated by PRO ( $\geq$ or $<30 \%$ ) and RT ( $\geq$ or $<1.5 \mathrm{ml} / \mathrm{min}$ ). ANOVA with post-hoc Bonferroni and multiple regression analyses were used. Results: OFS levels were correlated with GA. OT, PRO, and days from SOF-IOF were associated with OFS and GA, whereas RT was only correlated with OFS levels. Conclusions: OFS is a novel objective indicator of infants' feeding ability that takes into account infants' skills
\end{abstract}

and endurance. As a clinical tool, it can help caretakers monitor infants' skills as they transition to oral feeding and identify oral feeding issues arising from immature skills and/or poor endurance.

Copyright $\odot 2011$ S. Karger AG, Basel

\section{Introduction}

Attainment of independent oral feeding is one of the criteria recommended by the American Academy of Pediatrics for hospital discharge of preterm infants [1]. As such, an infant's inability to wean from tube feeding likely will delay hospital discharge and mother-infant reunion, while increasing medical cost and maternal stress $[2,3]$.

There are two dilemmas caregivers face when addressing oral feeding difficulties, i.e. infant ability to complete their feedings safely and the appropriate rate of advancement to independent oral feeding. Assessing infants' oral feeding skills has been difficult due to the lack of welldefined outcomes. Descriptive and objective scales have been developed. A descriptive scale uses visual, sensory and behavioral observations to assess the appropriateness of oral feeding skills, e.g. the Neonatal Oral-Motor Assessment Scale (NOMAS) developed by Palmer et al. [4] and the Early Feeding Skill assessment (EFS) by Thoyre et al. [5]. The accuracy of this type of approach has been 
debated due to its subjective nature and lack of direct measure of specific outcomes. Recently, a debate was raised regarding the validity of NOMAS when used in preterm infants insofar as this scale was developed from term infants $[6,7]$. Als et al. [8] have recommended the use of a developmental care approach to promote transition to oral feeding with the reasoning that if an infant's stability, organization and competence could be enhanced, his/her physiologic and behavioral expression would be optimized. Multidisciplinary approaches have also been proposed. An integrative assessment of an infant's potential ability to feed orally would be more accurate if feedback from the varied caregivers involved in his/her care were taken into account $[9,10]$. More objective and quantitative evaluations of feeding skills are illustrated by tools developed to measure outcomes such as nutritive and nonnutritive sucking patterns and their rhythmicity, sucking force and coordination of suckswallow-respiration [11-15]. However, these approaches necessitate special equipment, not readily available in neonatal intensive care units (NICU). Therefore, due to the difficulty in identifying the level of oral feeding skills (OFS), introduction and advancement of oral feeding remain in the hands of caregivers, with oral feeding customarily introduced around 33-35 weeks postmenstrual age (PMA).

In an earlier study [16] conducted at the first oral feeding of infants born between 26 and 30 weeks gestation (GA), we defined infants' OFS as a function of their combined proficiency (PRO, \% volume taken during the first $5 \mathrm{~min} /$ total volume prescribed) and rate of milk transfer over an entire feeding (RT, $\mathrm{ml} / \mathrm{min})$. PRO, being monitored during the first $5 \mathrm{~min}$ of a feeding, was used as an index of infants' actual feeding ability when fatigue is minimal. RT, being monitored over an entire feeding session, was used as an index of endurance. It was reasoned that during a feeding the rate of transfer would decrease if infants' actual skills were held back by increasing fatigue. We defined feeding as successful or not if infants completed $\geq 80 \%$ or $<80 \%$ of their prescribed feeding, respectively. Based on their performance, we distinguished 4 OFS levels as delineated by $\mathrm{PRO}>30 \%$ or $<30 \%$ and RT $>1.5$ or $<1.5 \mathrm{ml} / \mathrm{min}$. The cutoffs for these two outcomes were based on the observations that infants demonstrating $\mathrm{RT} \geq 1.5 \mathrm{ml} / \mathrm{min}$ and $\mathrm{PRO} \geq 30 \%$ were successful at feeding, i.e. taking $\geq 80 \%$ of their prescribed volume and attained independent oral feeding at an earlier PMA than counterparts whose PRO were $<30 \%$. Compared with this first group, infants with $\mathrm{RT} \geq 1.5 \mathrm{ml} /$ min, but PRO $<30 \%$, also fed successfully ( $\geq 80 \%)$, but attained independent oral feeding at a later PMA, whereas infants with $\mathrm{PRO}<30 \%$ and $\mathrm{RT}<1.5 \mathrm{ml} / \mathrm{min}$ were not successful at feeding $(<80 \%)$ and reached independent oral feeding at a later PMA.

This prospective study is a follow-up to our earlier work. Its goal was to determine whether the defined OFS levels can be used as an objective tool for the assessment of preterm infants' oral feeding skills. We hypothesized that (1) the more mature an infant's OFS level, the better his/her OT at that feeding; (2) the more premature an infant (GA), the more immature his/her OFS level, and (3) the better the OFS levels, the faster independent oral feeding will be attained.

\section{Methods}

Clinical Practice

Although breast-feeding is the optimal approach to infant feeding, in developed countries exclusive breast-feeding of hospitalized preterm infants is difficult to achieve. Thus, in the absence of mothers and when preterm infants are deemed ready to start oral feeding, bottle feeding is common practice rather than maintaining tube feeding. As is the practice at our hospital, our subjects' first oral feeding experience is with bottle rather than breast. Introduction and advancement of oral feeding are left to the discretion of the attending neonatologists. With no evidencebased determinant(s) of oral feeding readiness available, our attending neonatologists' decision to advance oral feeding generally takes into account their patients' clinical status, PMA, and the infants' oral feeding performance the day before if oral feeding started. It is also our hospital's practice that neonatal nutritionists monitor infants' daily weight to ensure at least a gain of $15 \mathrm{~g} / \mathrm{kg}$ body weight/day.

Subjects

Infants born between 26 and 36 weeks GA were recruited from the level II intermediate care nurseries at Texas Children's Hospital (Houston, Tex., USA). They were stratified into 3 GA strata: 26-29, 30-33 and 34-36 weeks GA. Exclusion criteria included gastrointestinal complications and various medical conditions, e.g. congenital cytomegalovirus, intraventricular hemorrhage grades III and IV. No infants with bronchopulmonary dysplasia were recruited as they remained in the level III NICU as per hospital protocol. Only 'feeders and growers' with a primary diagnosis of prematurity were enrolled. This diagnosis defined infants who were clinically stable, demonstrated clinical signs of immature systems, e.g. lung function, that resolved with maturation and whose discharge from the hospital was primarily based on their ability to feed by mouth. This study was approved by the Baylor College of Medicine Institutional Review Board for $\mathrm{Hu}-$ man Research. Parental consent was obtained following approval by attending neonatologists.

Outcome Measures

Infants were monitored at the time of their first oral feeding. They were identified by charge nurses who provided the infants' 
nurses with a study form to fill out immediately following the feeding session with the following information: total volume prescribed ( $\mathrm{ml})$, total volume taken during the feeding $(\mathrm{ml})$, volume taken during the first $5 \mathrm{~min}$ of the feeding $(\mathrm{ml})$, duration of oral feeding (min) and any episodes of adverse events, namely oxygen desaturation, apnea and/or bradycardia. Infants were fed for a maximum of $20 \mathrm{~min}$ as per nursery protocol, with nurses deciding on how long to feed based on their perception of infants' performance and endurance. Infants were not disturbed for at least $30 \mathrm{~min}$ prior to this feeding session in order to minimize fatigue prior to oral feeding. From the measures collected, the following outcomes were computed: overall transfer (OT, \% volume taken/ total volume to be taken); PRO (\% volume taken during the first $5 \mathrm{~min} /$ total volume prescribed); RT ( $\mathrm{ml} / \mathrm{min})$. The number of days taken from the start to independent oral feeding (SOF-IOF) was recorded. Four OFS levels were delineated by their respective PRO $(\geq 30 \%$ or $<30 \%$ ) and RT ( $\geq 1.5$ or $<1.5 \mathrm{ml} / \mathrm{min}$ ) as described in our earlier study [16]. Thus, level 1 , the most immature, was defined by $\mathrm{PRO}<30 \%$ and RT $<1.5 \mathrm{ml} / \mathrm{min}$, level 2 , by $\mathrm{PRO}<30 \%$ and $\mathrm{RT} \geq 1.5 \mathrm{ml} / \mathrm{min}$, level 3 , by $\mathrm{PRO} \geq 30 \%$ and $\mathrm{RT}<1.5 \mathrm{ml} / \mathrm{min}$, and level 4 , the most mature, by $\mathrm{PRO} \geq 30 \%$ and $\mathrm{RT} \geq 1.5 \mathrm{ml} / \mathrm{min}$. As in our earlier study, our working premises were as follows. $\mathrm{PRO}$, being monitored during the first $5 \mathrm{~min}$ of a feeding, is representative of infants' actual nutritive feeding skills as fatigue was deemed minimal (infants being undisturbed for $30 \mathrm{~min}$ prior to feeding). RT, being monitored over an entire feeding session, reflected infant overall skill when fatigue came into play and was used as an index of overall endurance (fig. 1).

Statistical analyses included univariate analyses of variance using Bonferroni for post-hoc comparisons when appropriate. Potential associations between outcomes and multiple factors were determined by multiple linear regression analyses (SPSS, v.17, Chicago, Ill., USA).

\section{Results}

Sixty-six subjects classified as 'feeders and growers' with a primary diagnosis of prematurity were recruited between March and September 2008. Their ethnic/racial and gender distribution are presented in table 1 . Table 2 shows infants' characteristics by GA strata. As expected, significant differences in GA, birth weight and days of life at first and independent oral feeding were noted between GA strata ( $p<0.001)$. Infants less than 34 weeks GA were introduced to oral feeding around 34-35 weeks PMA and within the first week of life for those born between 34 and 36 weeks GA. PMA at IOF was similar between GA strata (table 2), but significantly younger with more mature OFS levels (table 3). On the other hand, whereas PMA at discharge was significantly greater the more premature the infants (table 2), it was not significant between OFS levels (table 3). Multiple linear regression demonstrated that OFS levels were correlated with GA $(p=0.017)$ but not with PMA $(\mathrm{p}=0.234)$. With increasing GA, a trend



Fig. 1. Four OFS levels as defined by PRO and RT.

Table 1. Subjects' ethnic/racial and gender distribution

\begin{tabular}{lll}
\hline & Number & Percent \\
\hline Ethnicity/Race & & \\
$\quad$ Hispanic & 14 & 21 \\
$\quad$ Caucasian & 32 & 49 \\
$\quad$ African-American & 19 & 29 \\
$\quad$ Asian & 1 & 1 \\
Gender & & \\
$\quad$ Male & 36 & 55 \\
Female & 30 & 45 \\
\hline
\end{tabular}

was noted towards a gradual decrease in the predominance of the most immature OFS (level 1) with a concurrent increase in the more mature levels 2-4 (fig. 2). Subjects' oral feeding outcomes, i.e. OT, PRO, RT and feeding duration by GA strata and OFS levels, are presented in tables 2 and 3, respectively. None of these infants demonstrated any significant adverse events at their first oral feeding. OT and PRO were positively correlated with GA strata and OFS levels ( $\mathrm{p} \leq 0.004$ ), and a negative association was noted with feeding duration $(\mathrm{p} \leq 0.014)$. RT did not differ between GA strata $(p=0.172)$ but did between OFS levels ( $p<0.001)$. Multiple linear regression analyses showed associations between oral feeding outcomes with OFS levels, GA and PMA ( $\mathrm{p} \leq$ 0.022; table 4). Post-hoc analyses demonstrated that OT, PRO and days from SOF to IOF were primarily associated with OFS levels and GA. In turn, RT was only with OFS levels and feeding duration with GA strata. Average days from SOF-IOF by OFS levels and GA strata are presented in table 5.

In an attempt to determine the individual effect of infants' actual feeding skills (as measured by PRO when 
Table 2. Characteristics and oral feeding outcomes of subjects who attained independent oral feeding prior to discharge

\begin{tabular}{|c|c|c|c|c|}
\hline & \multicolumn{4}{|l|}{ GA strata, weeks } \\
\hline & $26-29$ & $30-33$ & $34-36$ & $\mathrm{p}^{1}$ \\
\hline Number & 20 & 39 & 7 & \\
\hline GA, weeks & $27.9 \pm 1.2$ & $31.8 \pm 1.1$ & $34.8 \pm 0.8$ & $<0.001$ \\
\hline Birth weight, $g$ & $1,047.9 \pm 194.8^{\mathrm{a}, \mathrm{b}}$ & $1,545.2 \pm 305.4^{\mathrm{a}, \mathrm{c}}$ & $2,275.1 \pm 444.8^{\mathrm{b}, \mathrm{c}}$ & $<0.001$ \\
\hline DOL at SOF & $53 \pm 33^{\mathrm{a}, \mathrm{b}}$ & $17 \pm 9^{a}$ & $5 \pm 5^{\mathrm{b}}$ & $<0.001$ \\
\hline PMA at SOF & $35.4 \pm 4.3$ & $34.2 \pm 0.9$ & $35.5 \pm 1.0$ & 0.149 \\
\hline DOL at IOF & $62 \pm 17^{a, b}$ & $28 \pm 11^{\mathrm{a}, \mathrm{c}}$ & $10 \pm 7^{b, c}$ & $<0.001$ \\
\hline PMA at IOF & $36.9 \pm 2.5$ & $35.8 \pm 1.2$ & $36.2 \pm 1.1$ & 0.112 \\
\hline PMA at discharge & $40.1 \pm 4.9^{\mathrm{a}, \mathrm{b}}$ & $37.3 \pm 1.8^{\mathrm{a}}$ & $36.9 \pm 1.0^{\mathrm{b}}$ & 0.004 \\
\hline OT, $\%$ & $46.6 \pm 35.5^{\mathrm{a}}$ & $53.0 \pm 33.4^{\mathrm{b}}$ & $95.2 \pm 12.6^{\mathrm{a}, \mathrm{b}}$ & 0.004 \\
\hline $\mathrm{PRO}, \%$ & $21.3 \pm 18.8^{\mathrm{a}}$ & $28.4 \pm 24.8^{\mathrm{b}}$ & $57.1 \pm 26.3^{\mathrm{a}, \mathrm{b}}$ & 0.004 \\
\hline $\mathrm{RT}, \mathrm{ml} / \mathrm{min}$ & $1.0 \pm 1.1$ & $1.1 \pm 0.7$ & $1.7 \pm 1.1$ & 0.172 \\
\hline Feeding duration, min & $17 \pm 5^{\mathrm{a}, \mathrm{b}}$ & $14 \pm 5^{\mathrm{a}}$ & $11 \pm 5^{\mathrm{b}}$ & 0.014 \\
\hline
\end{tabular}

Means $\pm \mathrm{SD} . \mathrm{GA}=$ Gestational age DOL = days of life; SOF = start of oral feeding; PMA = postmenstrual age (weeks); IOF $=$ independent oral feeding (8 oral feedings/day).

${ }^{1}$ One-way ANOVA; post-hoc Bonferroni between different superscript letters $\mathrm{p} \leq 0.05$.

Table 3. Oral feeding performance at first oral feeding by OFS level (mean \pm SD)

\begin{tabular}{|c|c|c|c|c|c|}
\hline & \multicolumn{5}{|l|}{ OFS level } \\
\hline & 1 & 2 & 3 & 4 & $\mathrm{p}^{1}$ \\
\hline Number & 36 & 5 & 14 & 11 & \\
\hline Infants at each level, \% & 54.5 & 7.6 & 21.2 & 16.7 & \\
\hline OT, $\%$ & $30.3 \pm 23.6^{\mathrm{a}-\mathrm{c}}$ & $84.8 \pm 16.5^{\mathrm{a}}$ & $77.9 \pm 21.1^{\mathrm{b}, \mathrm{d}}$ & $96.3 \pm 12.3^{\mathrm{c}, \mathrm{d}}$ & $<0.001$ \\
\hline $\mathrm{PRO}, \%$ & $12.5 \pm 7.3^{\mathrm{a}, \mathrm{b}}$ & $23.1 \pm 3.6^{\mathrm{c}, \mathrm{d}}$ & $47.3 \pm 20.2^{\mathrm{a}, \mathrm{c}, \mathrm{e}}$ & $64.4 \pm 22.8^{\mathrm{b}, \mathrm{d}, \mathrm{e}}$ & $<0.001$ \\
\hline $\mathrm{RT}, \mathrm{ml} / \mathrm{min}$ & $0.6 \pm 0.4^{\mathrm{a}-\mathrm{c}}$ & $1.9 \pm 0.3^{\mathrm{a}, \mathrm{d}, \mathrm{e}}$ & $1.0 \pm 0.2^{\mathrm{b}, \mathrm{d}, \mathrm{f}}$ & $2.6 \pm 1.0^{c, e, f}$ & $<0.001$ \\
\hline Feeding duration, min & $14.9 \pm 4.9^{\mathrm{a}}$ & $17.4 \pm 2.5^{\mathrm{b}}$ & $15.9 \pm 5.4^{\mathrm{c}}$ & $9.8 \pm 4.7^{\mathrm{a}-\mathrm{c}}$ & 0.007 \\
\hline PMA at IOF, weeks & $36.8 \pm 1.9^{\mathrm{a}, \mathrm{b}}$ & $35.9 \pm 1.1$ & $35.6 \pm 1.0^{\mathrm{a}}$ & $35.2 \pm 1.4^{\mathrm{b}}$ & 0.020 \\
\hline PMA at discharge, weeks & $38.9 \pm 3.9$ & $37.3 \pm 1.1$ & $37.6 \pm 2.0$ & $36.4 \pm 1.4$ & 0.102 \\
\hline
\end{tabular}

${ }^{1}$ One-way ANOVA; post-hoc Bonferroni between different superscript letters $\mathrm{p} \leq 0.05$.

fatigue was minimal) and endurance (as measured by $\mathrm{RT}$ ) on overall transfer (OT), infants were divided into two groups, i.e. 'high' and 'low' actual skill level as defined by $\mathrm{PRO} \geq 30 \%$ and $<30 \%$, respectively (fig. 3). Twoway ANOVA showed that significant PRO and RT effects along with a significant interaction between $\mathrm{PRO} \cdot \mathrm{RT}$ on OT $(\mathrm{p}<0.001)$. OT of infants in the high-PRO groups (OFS levels 3 and 4) were significantly greater than of those of their low-PRO counterparts (OFS levels 1 and 2). Similarly, infants in the high RT ( $\geq 1.5 \mathrm{ml} / \mathrm{min}$, OFS levels 2 and 4) performed better than counterparts with low RT ( $<1.5 \mathrm{ml} / \mathrm{min}$, OFS levels 1 and 3). Post-hoc analyses of PRO·RT demonstrated that infants at an OFS level 1 (low PRO, low RT) performed significantly worse than counterparts at levels $2-4(\mathrm{p}<0.001)$. No differences were observed between infants at OFS levels $\geq 2(p \geq 0.210)$.

\section{Discussion}

Caregivers frequently question the 'oral feeding readiness' of preterm infants when considering introduction of oral feeding. As no accurate tool is available to determine whether an infant is 'ready' to wean from tube feed- 




Fig. 2. Percent distribution of OFS levels by GA stratum in infants born between 26 and 36 weeks gestation.

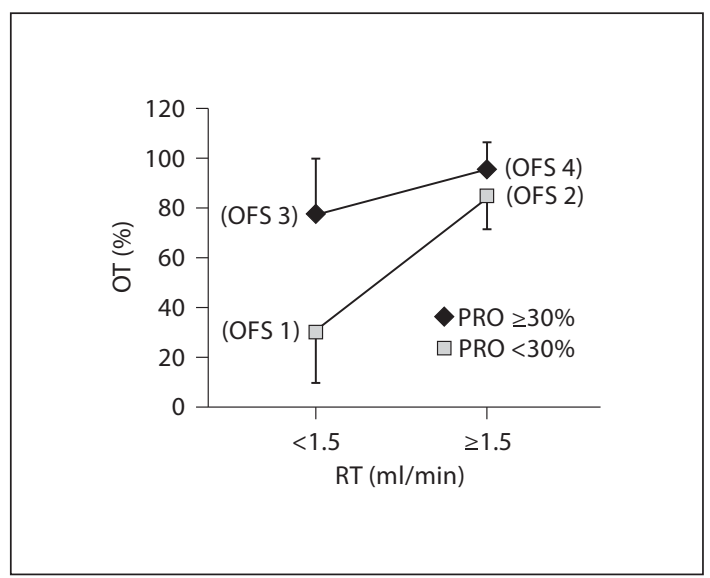

Fig. 3. OT of infants with high versus low actual feeding skills (PRO $>30 \% /<30 \%)$ vs. endurance (RT $>1.5 /<1.5 \mathrm{ml} / \mathrm{min}$ ).

Table 4. Multiple regression analyses of oral feeding outcomes by OFS levels, GA strata and PMA category

\begin{tabular}{lcccc}
\hline & OFS level & GA strata & PMA category & $p$ \\
\hline OT, \% & $<0.001$ & 0.053 & 0.431 & $<0.001(64.4)^{\mathrm{a}}$ \\
PRO, \% & $<0.001$ & 0.034 & 0.180 & $<0.001(70.0)$ \\
RT, ml/min & $<0.001$ & 0.714 & 0.928 & $<0.001(43.9)$ \\
Feeding duration, min & 0.274 & 0.013 & 0.440 & $<0.022(10.5)$ \\
SOF-IOF, days & 0.003 & $<0.001$ & 0.080 & $<0.001(39.5)$ \\
\hline
\end{tabular}

${ }^{\text {a }}$ Figures in parentheses are adj. R2 (expressed in percentages).

Table 5. Time from introduction to attainment of independent oral feeding

\begin{tabular}{|c|c|c|c|c|c|c|c|c|c|}
\hline & \multicolumn{4}{|c|}{ GA strata, weeks } & \multicolumn{5}{|c|}{ OFS levels } \\
\hline & $26-29$ & $30-33$ & $34-36$ & $\mathrm{p}^{1}$ & 1 & 2 & 3 & 4 & $\mathrm{p}^{1}$ \\
\hline SOF to IOF, days & $20 \pm 11^{\mathrm{a}, \mathrm{b}}$ & $13 \pm 5^{a}$ & $5 \pm 3^{b}$ & $<0.001$ & $17 \pm 9^{a, b}$ & $14 \pm 7$ & $12 \pm 6^{a}$ & $7 \pm 4^{\mathrm{b}}$ & 0.002 \\
\hline
\end{tabular}

${ }^{1}$ One-way ANOVA; post-hoc Bonferroni between different superscript letters $\mathrm{p} \leq 0.05$.

ing, introduction and advancement of oral feedings are commonly ordered by attending physicians, with some practices leaving the decision to nurses or following prefeeding assessment programs such as those of Thoyre et al. [5] and McCain [17]. Infants with oral feeding issues are routinely referred to feeding therapists. However, if any improvement occurs, it is uncertain whether it resulted from normal maturation or the therapies provided as evidence-based data lack in supporting the latter's benefit(s).

This study was conducted to determine whether OFS levels as defined by the combination of PRO and RT may be used as an objective indicator of infants' feeding skills. Our hypotheses were confirmed insofar as the OFS levels were (1) positively correlated with an infant's feeding performance, i.e. the better the levels, the greater the OT and 
Table 6. OFS levels as potential screening tool for assessment of infants' actual feeding skills and endurance

\begin{tabular}{llll}
\hline $\begin{array}{l}\text { OFS level } \\
(\mathrm{OT})\end{array}$ & $\begin{array}{l}\text { Actual feeding } \\
\text { skills (PRO) }\end{array}$ & $\begin{array}{l}\text { Endurance } \\
\text { (RT) }\end{array}$ & Potential intervention(s) \\
\hline 1 & low & low & $\begin{array}{l}\text { nonnutritive oral motor } \\
\text { stimulation + endurance } \\
\text { training }\end{array}$ \\
\hline 2 & low & high & $\begin{array}{l}\text { nonnutritive oral motor } \\
\text { stimulation }\end{array}$ \\
\hline 3 & high & low & endurance training \\
\hline 4 & high & high & none \\
\hline
\end{tabular}

the shorter the feeding duration; (2) positively correlated with GA strata, i.e. the less premature the infant, the more mature his/her skills, and (3) inversely associated with days from SOF to IOF, i.e. the better the skills, the faster the attainment of independent oral feeding.

It is unclear why infants within a particular GA stratum, even the most premature one, exhibited all 4 levels of OFS when tested at the same PMA. Prenatal factors may have been involved. The lack of correlation between oral feeding outcomes and PMA was expected insofar as infants were introduced to oral feeding at similar PMA. The associations of OT and PRO with OFS levels helps explain why some infants of similar gestational and/or postnatal ages readily transition from tube to oral feeding while others do not. Indeed, we showed that infants within each GA stratum exhibited OFS levels ranging from 1 to 4 . Consequently, the use of GA may not be the optimal indicator for assisting the decision-making of caregivers in the initiation and advancement of oral feeding in preterm infants. The correlations of $O T$ and $P R O$ with $G A$ can be explained by the greater proportion of infants in the older GA strata that naturally demonstrated more mature OFS levels. The observation that $R T$ was associated with OFS, but not GA, suggests that RT is primarily regulated by an infant's feeding aptitude, e.g. suck, swallow, suck-swallow-respiration coordination and/or endurance. This is supported by an earlier work where we showed that infants feeding with nipples of varied flow rates within a 24 -hour period could modify their sucking skills, e.g. sucking pattern and suction amplitude, in order to maintain the same RT [18]. The correlation between feeding duration and GA is consistent with the lower PRO, OT and the trend towards slower RT observed at the younger GA. The association of days from SOF-IOF with both OFS levels and GA supports the notion that feeding performance resulting from infants' OFS levels and GA are criteria used by our attending physicians in advancing oral feeding. Infants with high $P R O(\geq 30 \%$, OFS levels 3 and 4) perform better than their counterparts with low PRO ( $<30 \%$, OFS levels 1 and 2$)$. Similarly, infants with high RT (OFS levels 2 and 4) also performed better than infants with low RT (OFS levels 1 and 3). The observation that infants at OFS levels 2 and 3 had similar OT suggests that both actual feeding skill and endurance are equally important in determining oral feeding success. From this, one may speculate that enhancing both factors would optimize outcome. This is supported by the observations that OT, PRO, RT and feeding duration of infants at OFS level 4 were superior to those of their counterparts at levels 1-3.

From this study, it is proposed that the use of OFS levels can offer a more objective indicator of infants' ability to feed by mouth than GA or other tools currently available. It does not claim to provide the ultimate answer for solving infants' oral feeding difficulties as the latter are multifactorial. However, it offers the possibility of differentiating between feeding aptitude and endurance/fatigue which, as we showed, are both equally important for oral feeding success. Its use offers several advantages. (1) It is easy to measure as caregivers need only collect the volume reading at $5 \mathrm{~min}$ into the feeding session in addition to the routine information collected, i.e. volume prescribed, volume taken and feeding duration. No special equipment is required. (2) It provides an objective rather than subjective assessment of infants' feeding skills during a feeding session. (3) As infants of similar GA differ in OFS, evaluating their levels prior to the introduction of oral feeding can help identify infants' ability when oral feeding is initiated. (4) Measuring OFS levels does not only pertain to infants' first oral feeding. Monitoring OFS longitudinally as infants wean from tube feeding provides information on their maturation process. It can be used as an indicator of whether oral feeding should be advanced or held back. Additionally, if an infant is receiving a particular intervention, monitoring over time can help determine its efficacy. (5) OFS levels may also assist caregivers in identifying whether infants' oral feeding issues relate to skill levels or endurance (table 6). For instance, if an infant exhibits an OFS level of 1 , with low skill and endurance, he/she may benefit from oral feeding therapy and 'endurance training' (see below). A level 2 infant with low skill and high endurance would likely only require oral feeding therapy, whereas a level 3 infant with high skill and low endurance would benefit from 
'endurance training'. An infant at level 4 would need no intervention. Oral feeding therapy to enhance actual feeding skills may consist of a nonnutritive oral motor stimulation program, which has been shown to accelerate attainment of IOF [19-21]. In order to prevent negative oral feeding experiences and/or excessive fatigue [22], it is proposed that an 'endurance training' program be set up. This may consist of daily shortened feeding sessions, the total duration of which equals the duration corresponding to the number of oral feedings per day ordered. For instance, if an infant is allowed to feed once a day for a maximum of $20 \mathrm{~min}$, but at the first feeding on that day, after $5 \mathrm{~min}$ he/she exhibits signs of fatigue, disorganization and/or unstable behavioral state, the 'endurance training' may consist of four 5-min feedings on that particular day. Feeding duration can be gradually increased on a daily basis as the above symptoms decrease. Although no study, to the authors' knowledge, has yet been conducted to show that such training program is efficacious, it is based on the general acceptance that 'practice makes perfect' in the absence of adverse events.

In summary, we propose that the use of OFS levels is an additional indicator to assist caregivers in determining infants' oral feeding aptitude. It is novel and offers an objective assessment of oral feeding skills whether they are monitored at a first oral feeding experience or on a regular basis as they advance towards independent oral feeding.

\section{Acknowledgments}

The authors are grateful to all the nurses in the level II intermediate care nurseries at Texas Children's Hospital for their enthusiasm in assisting with data collection. Special recognition is given to Clarito Arbilo, RN, who supervised the entire study and Averie Swanson, undergraduate research assistant for data management. This work was supported by a grant from the National Institute of Child Health and Human Development (R01HD044469). The contents of this publication are solely the responsibility of the authors and do not necessarily represent the official views of the National Institute of Child Health and $\mathrm{Hu}$ man Development or the National Institutes of Health.

\section{Disclosure Statement}

The authors have no financial disclosure or conflict of interest to disclose relevant to this article.

\section{References}

1 American Academy of Pediatrics: Hospital discharge of the high-risk neonate. Pediatrics 2008;122:1119-1126.

-2 Lau C, Hurst N: Oral feeding in infants. Curr Probl Pediatr 1999;29:105-124.

3 Burklow KA, McGrath AM, Kaul A: Management and prevention of feeding problems in young children with prematurity and very low birth weight. Infants Young Children 2002;14:19-30.

-4 Palmer MM, Crawley K, Blanco IA: Neonatal Oral-Motor Assessment scale: a reliability study. J Perinatol 1993;13:28-35.

5 Thoyre SM, Shaker CS, Pridham KF: The early feeding skills assessment for preterm infants. Neonatal Netw 2005;24:7-16.

6 da Costa SP, van der Schans CP: The reliability of the Neonatal Oral-Motor Assessment Scale. Acta Paediatr 2008;97:21-26.

7 da Costa SP, van den Engel-Hoek L, Bos AF: Sucking and swallowing in infants and diagnostic tools. J Perinatol 2008;28:247-257.

-8 Als H, Lawhon G, Duffy FH, McAnulty GB, Gibes-Grossman R, Blickman JG: Individualized developmental care for the very lowbirth-weight preterm infant. Medical and neurofunctional effects (see comments). JAMA 1994;272:853-858.
-9 Rommel N, De Meyer AM, Feenstra L, Veereman-Wauters G: The complexity of feeding problems in 700 infants and young children presenting to a tertiary care institution. $\mathrm{JP}$ diatr Gastroenterol Nutr 2003;37:75-84.

10 Premji SS, McNeil DA, Scotland J: Regional neonatal oral feeding protocol: changing the ethos of feeding preterm infants. J Perinat Neonatal Nurs 2004;18:371-384.

11 Medoff-Cooper B, Verklan T, Carlson S: The development of sucking patterns and physiologic correlates in very-low-birth-weight infants. Nurs Res 1993;42:100-105.

12 Lau C, Alagugurusamy R, Schanler RJ, Smith EO, Shulman RJ: Characterization of the developmental stages of sucking in preterm infants during bottle feeding. Acta Paediatr 2000;89:846-852.

13 Poore M, Zimmerman E, Barlow SM, Wang J, Gu F: Patterned orocutaneous therapy improves sucking and oral feeding in preterm infants. Acta Paediatr 2008;97:920-927.

14 Gewolb IH, Vice FL: Maturational changes in the rhythms, patterning, and coordination of respiration and swallow during feeding in preterm and term infants. Dev Med Child Neurol 2006;48:589-594.

15 Lau C, Smith EO, Schanler RJ: Coordination of suck-swallow and swallow respiration in preterm infants. Acta Paediatr 2003;92:721727.
16 Lau C, Sheena HR, Shulman RJ, Schanler RJ: Oral feeding in low birth weight infants. J Pediatr 1997;130:561-569.

17 McCain GC: An evidence-based guideline for introducing oral feeding to healthy preterm infants. Neonatal Netw 2003;22:45-50.

18 Scheel CE, Schanler RJ, Lau C: Does the choice of bottle nipple affect the oral feeding performance of very-low-birthweight (VLBW) infants? Acta Paediatr 2005;94: 1266-1272.

19 Fucile S, Gisel E, Lau C: Oral stimulation accelerates the transition from tube to oral feeding in preterm infants. J Pediatr 2002; 141:230-236.

20 Fucile S, Gisel EG, Lau C: Effect of an oral stimulation program on sucking skill maturation of preterm infants. Dev Med Child Neurol 2005;47:158-162.

21 Rocha AD, Moreira ME, Pimenta HP, Ramos JR, Lucena SL: A randomized study of the efficacy of sensory-motor-oral stimulation and non-nutritive sucking in very low birthweight infant. Early Hum Dev 2007;83:385388.

22 Lau C: Oral feeding in the preterm infant. NeoReviews 2006;7:e19-e27. 